\title{
MEHR ZUM THEMA NUTZFAHRZEUG
}

Liebe Leserin, lieber Leser,

der erste Internationale Motorenkongress von ATZlive und dem VDI Wissensforum war ein voller Erfolg: 388 Teilnehmer verfolgten 46 Keynotes und Fachvorträge sowie die Podiumsdiskussion zur gesamten Architektur des Motors, sowohl für Pkw- als auch Nutzfahrzeuganwendungen. Im Mittelpunkt standen die Themen Grundmotor, Ladungswechsel, Verbrennung, Abgasnachbehandlung, Motormanagement und Thermomanagement. 20 Aussteller zeigten ihr Portfolio den interessierten Teilnehmern. Lesen Sie mehr zum Internationalen Motorenkongress auf den Seiten 10 und 11.

Ganz bewusst wurde in Baden-Baden das Thema Nutzfahrzeuge als eigener Strang angelegt, und die Rückmeldungen dazu waren überaus positiv. Daher wird ab 2015 eine eigene NutzfahrzeugKonferenz im Rahmen des Internationalen Motorenkongresses durchgeführt. Die zeitliche und räumliche direkte Nähe zum „Mutterschiff Motorenkongress" fördert dabei den Informationsund Meinungsaustausch der benachbarten Disziplinen.

Ein hochkarätiger Programmbeirat bürgt auch bei der Nutzfahrzeug-Konferenz für eine weiterhin hohe Qualität der Vorträge. Da beim Nutzfahrzeug anders als beim Pkw die Total Cost of Ownership klar im Vordergrund steht, liegt der Fokus neben internationalen Kraftstoffqualitäten vor allem auf dem Thema $\mathrm{CO}_{2}$-Reduktion. Reibungsminimierung im Grundmotor und Optimierung der Brennverfahren werden daher im kommenden Jahr mit Sicherheit bestimmende Themen dieses neuen Nutzfahrzeugkongresses sein.

Die MTZ hat sich zu Ziel gesetzt, den Nutzfahrzeugbereich noch stärker zu beachten. Mehr Fachbeiträge zu diesem Thema und der Internationale Motorenkongress sind wichtige Bausteine hierfür. Ebenso beachtenswert ist das ATZextra zur Nutzfahrzeug-IAA im September in Hannover, das ATZ und MTZ gemeinsam „auf die Straße“ bringen werden. Wir freuen uns schon heute auf Themen aus Ihren Häusern.

Herzlichst, Ihr

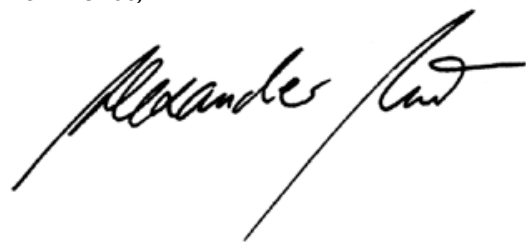

DR. ALEXANDER HEINTZEL, Chefredakteur Wiesbaden, 14. März 2014

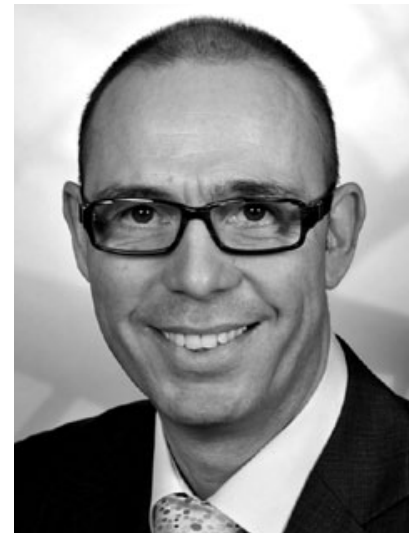

INNOVATION

IST UNSER MOTOR SEIT 75 JAHREN.

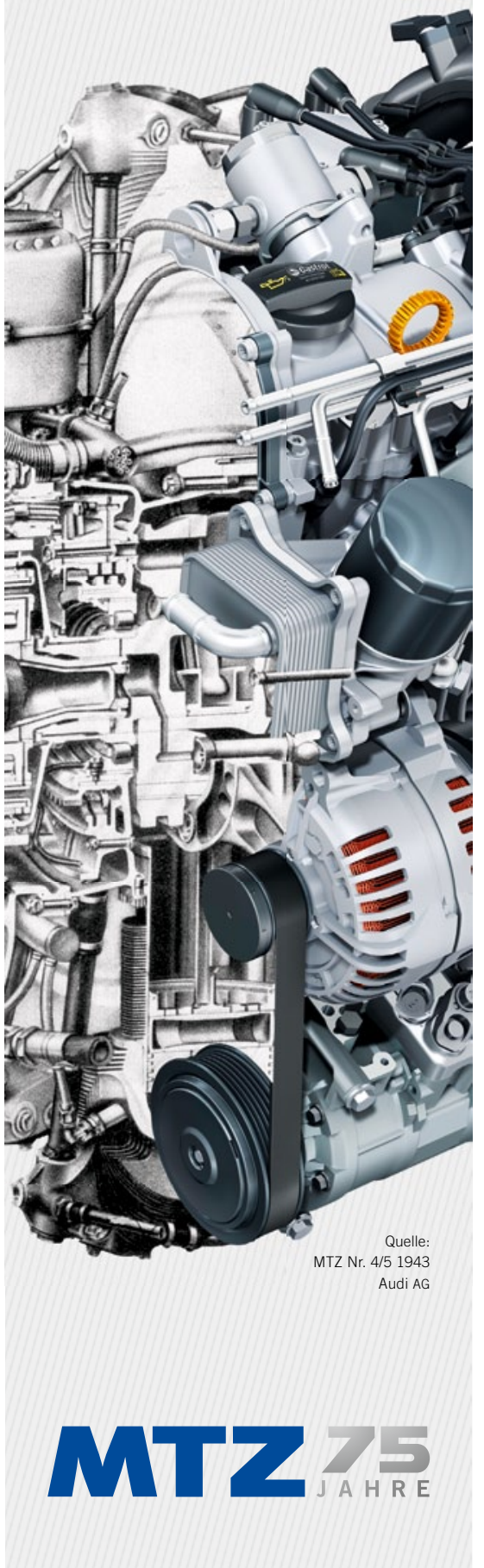

